\title{
Comparison of portal and peripheral insulin delivery on carbohydrate metabolism in streptozotocin-diabetic rats
}

\author{
Y.T. Kruszynska, P. D. Home and K.G. M. M. Alberti \\ Department of Clinical Biochemistry and Metabolic Medicine, University of Newcastle upon Tyne, Newcastle upon Tyne, UK
}

\begin{abstract}
Summary. Severely diabetic rats $(150 \mathrm{mg}$ streptozotocin $/ \mathrm{kg})$ were transplanted with fetal pancreatic islets: (a) under the kidney capsule to model peripheral insulin delivery, and (b) into the splenic pulp to model portal delivery. Long-term normoglycaemia, normal weight gain and normal peripheral insulin levels were achieved in both groups of transplanted animals. In both groups, 24-h fasted blood lactate, pyruvate and alanine were identical to those observed in sham-operated control animals. Blood glucose and plasma insulin responses to $300 \mathrm{mg}$ oral glucose 8 weeks after transplantation were the same as in control animals. Hepatic glycogen concentration was, however, lower in fed rats with islets beneath the kidney capsule compared with control rats $(p<0.01)$, suggesting inadequate hepatic insulinisation in the fed state with peripher-
\end{abstract}

al insulin delivery. Muscle glycogen was the same as in controls. Glucose turnover and glucose carbon recycling were not significantly different from results in normal control and splenic pulp islet-transplanted animals. The findings indicate that consistent normoglycaemia, normal glucose flux and normalisation of blood intermediary metabolites can be achieved in the rat with peripheral insulin delivery without associated hyperinsulinaemia.

Key words: Islet transplantation, streptozotocin-diabetic rat, peripheral hyperinsulinaemia, oral glucose tolerance test, insulin, glucose, lactate, glucose turnover, glucose carbon recycling.

the splenic pulp (portal venous drainage) and normal control animals.

The aims of the study were to establish whether long-term normoglycaemia could be achieved in streptozotocin-diabetic rats with peripheral insulin delivery, and to ascertain whether this was associated with peripheral hyperinsulinaemia. We have also determined the extent of the disturbance of intermediary metabolism in these animals, and investigated whether abnormalities of glucose turnover and recycling are still found.

\section{Materials and methods}

\author{
Animals \\ Syngeneic Wistar Boots rats (Nottingham University, Nottingham, \\ UK) were used both for the isolation of pancreatic islets and metabol- \\ ic studies. Rats were fed on laboratory chow (71\% carbohydrate, $22 \%$ \\ protein, $7 \%$ fat) and housed in a room with light and dark cycles com- \\ mencing at 0700 and 1900 hours. Indwelling cannulae for metabolic \\ studies were implanted under ether anaesthesia in the external jugular \\ vein, and in a femoral vein when required, $24 \mathrm{~h}$ before the experiment.
}




\section{Induction of diabetes and insulin therapy}

Diabetes was induced in male rats $(110-130 \mathrm{~g})$ by intravenous injection of streptozotocin (Sigma, Poole, Dorset, UK; $0.15 \mathrm{~g} / \mathrm{kg}$, in $0.01 \mathrm{~mol} / 1$ citrate buffer, $\mathrm{pH} 4.5$ ) under ether anaesthesia. Control animals were injected with citrate buffer only. Diabetes was confirmed by blood glucose estimation and weight loss at $18 \mathrm{~h}$. Rats were maintained from the first day after injection of streptozotocin by daily subcutaneous injection of highly purified beef protamine zinc insulin (Hypurin, CPI Pharmaceuticals, Wrexham, Clwyd, UK). After islet transplantation insulin was continued at $2 \mathrm{U} /$ day for 2 weeks and then withdrawn. In a group of non-transplanted rats $(n=19)$, withdrawal of insulin therapy 4 months after induction of diabetes invariably led to death from ketoacidosis. Rats treated with streptozotocin $(150 \mathrm{mg} / \mathrm{kg}) \mathrm{had}$ normal plasma creatinine and liver function when checked 4 weeks after injection of the drug.

\section{Islet culture and transplantation}

Pancreatic islets were isolated from fetuses at 22 days gestation as described by Hellerström et al. [11]. They were cultured in RPMI 1640 medium (Flow Laboratories, Irvine, Scotland) containing glucose $(11.1 \mathrm{mmol} / 1)$ and supplemented with Hepes $(20 \mathrm{mmol} / 1)$, penicillin $(100000 \mathrm{U} / \mathrm{l})$, streptomycin $(0.1 \mathrm{~g} / \mathrm{l})$ and $100 \mathrm{ml} / 1$ heat-inactivated fetal calf serum (Flow Laboratories). After 5 days, islets devoid of nonendocrine tissue were handpicked and cultured free-floating for 1-2 days. Five days after induction of diabetes, islets in a volume of $100 \mu \mathrm{l}$ of culture medium were transplanted either under the kidney capsule to model peripheral insulin delivery or into the splenic pulp to model portal insulin delivery. Following preliminary observations (unpublished), 5000 islets were transplanted into either the splenic pulp or under the kidney capsule to achieve consistent normoglycaemia. Control animals were sham-operated. Metabolic studies were performed 8-10weeks after transplantation when rats weighed $250-300 \mathrm{~g}$.

\section{Oral glucose tolerance test}

Nine splenic pulp and eight kidney capsule islet-transplanted rats were studied, together with 10 control animals. Studies were begun at $0900 \mathrm{~h}$, and were carried out on 24-h fasted unrestrained, unanaesthetised animals. Rats drank $300 \mathrm{mg}$ glucose in $0.75 \mathrm{ml}$ water over $60 \mathrm{~s}$ from a hand-held plastic cannula. Blood samples were taken frequently from -30 to $120 \mathrm{~min}$ (Fig. 1), and replaced with an equal volume of saline $(0.15 \mathrm{~mol} / \mathrm{l})$. Plasma was separated immediately and stored at $-40^{\circ} \mathrm{C}$ until analysed. Blood glucose was estimated on fluoride samples within $4 \mathrm{~h}$.

\section{Radioisotopic glucose turnover}

Glucose turnover was measured in 11 kidney capsule islet-transplanted, 11 splenic pulp-transplanted, and 15 control rats. Studies were performed on $24 \mathrm{~h}$ fasted unanaesthetised, unrestrained rats. A basal blood sample was taken at 0900 hours for estimation of blood glucose and intermediary metabolite concentrations. $3{ }^{3} \mathrm{H}$-glucose $(10 \mu \mathrm{Ci})$ and $\mathrm{U}^{14} \mathrm{C}$-glucose $(6 \mu \mathrm{Ci})$ (Amersham International, Amersham, Bucks, UK) in $250 \mu \mathrm{l}$ water were given by injection at time $0 \mathrm{~min}$ into the femoral cannula and flushed with saline $(300 \mu \mathrm{l}, 0.15 \mathrm{~mol} / \mathrm{l})$. The exact volume of tracer injected was determined by weighing the syringes before and after administration of tracer. Blood samples $(200 \mu 1)$ were taken from the jugular cannula every 3 min until 15 min, then at 30,45 and $60 \mathrm{~min}$, and every $30 \mathrm{~min}$ until $240 \mathrm{~min}$, and replaced with washed erythrocytes in saline $(200 \mu \mathrm{l}, 0.15 \mathrm{~mol} / \mathrm{l})$.

Plasma was separated immediately and $100 \mu \mathrm{l}$ deproteinised with barium hydroxide:zinc sulphate [12] and the neutral extract passed down a column of AG2-X8 anion exchange resin (Bio-Rad, Richmond, California, USA). The column was eluted with deionised water, and the eluate freeze-dried. Radioactivity was determined in a liquid scintillation counter (LKB Wallac 1217, Rackbeta, London, UK), using an external standard to correct for efficiency and overlapping. Minimum recovery after deproteinisation, neutralisation, passage through the column, and freeze-drying was $94 \%$. At each time point, a sample of plasma was taken for determination of glucose concentration.

Glucose turnover was estimated from the reduction of $3-{ }^{3} \mathrm{H}$-glucose specific activity over $4 \mathrm{~h} \mathrm{[13]:}$

Glucose turnover: $\frac{\text { injected dose }(\mathrm{dpm} / \mathrm{kg})}{\int_{0}^{\infty} \text { glucose specific activity dt }}$

Radioactive glucose recycling, as defined by Streja et al. [14], was estimated by the difference between the glucose turnover calculated by the ${ }^{3} \mathrm{H}$-glucose method and the ${ }^{14} \mathrm{C}$-glucose method [14].

Percentage recycling: $\frac{\mathrm{RT}^{3} \mathrm{H}-\mathrm{RT}^{14} \mathrm{C}}{\mathrm{RT}^{3} \mathrm{H}} \times 100$

The coefficient of variation of plasma glucose concentration during the turnover studies was $8.0 \pm 3.4 \%$ (mean $\pm \mathrm{SD}$ ).

\section{Tissue glycogen determination}

Rats fed ad libitum or fasted for $24 \mathrm{~h}$, were killed between 0900 and $1000 \mathrm{~h}$ by a blow to the head, and samples of liver and muscle freezeclamped, ground in liquid nitrogen, and stored at $-70{ }^{\circ} \mathrm{C}$ until assayed. For glycogen determination samples $(\sim 0.5 \mathrm{~g})$ were homogenised (Polytron Kinematica, Lucerne, Switzerland) in perchloric acid $(0.6 \mathrm{~mol} / \mathrm{l})$ and the supernatant incubated with amyloglucosidase (Sigma) [15]. Liberated glucose was assayed by an automated hexokinase method [16]. Tissue glycogen as glucosyl residues was calculated after subtraction of the glucose concentration in unhydrolysed samples. Complete hydrolysis by amyloglucosidase was checked by parallel assay of a standard preparation.

\section{Blood intermediary metabolites and plasma insulin}

Blood for estimation of intermediary metabolites in the ad libitum fed state was obtained at 0900 hours from the tail vein of animals under ether anaesthesia. Blood was deproteinised with perchloric acid $(0.6 \mathrm{~mol} / \mathrm{l})$ and the extract assayed within 1 week for lactate, pyruvate and alanine using automated enzymic fluorimetric methods [16]. Plasma or blood glucose was measured by a glucose oxidase method (Yellow Springs Glucose Analyser, Clandon Scientific, London, UK) and insulin by radioimmunoassay [17] using a rat insulin standard (Novo Industri, Bagsvaerd, Denmark).

\section{Statistical methods and calculations}

Results are presented as mean \pm SEM. Significant differences between the groups were assessed by Student's t-test, and regression and correlation by standard parametric methods.

\section{Results}

\section{Oral glucose tolerance test}

Fasting blood glucose and plasma insulin levels did not differ between the two groups of transplanted animals, nor from the controls (Table 1). Median peak glucose concentration was achieved at $15 \mathrm{~min}$ in all animal groups. At no time was there any statistically significant difference in blood glucose concentration between the three groups of animals (Fig.1), the apparent elevation of mean blood glucose from 20 to $40 \mathrm{~min}$ in the kidney capsule islet-transplanted group reflecting a higher response in only two of the eight animals studied. No dif- 


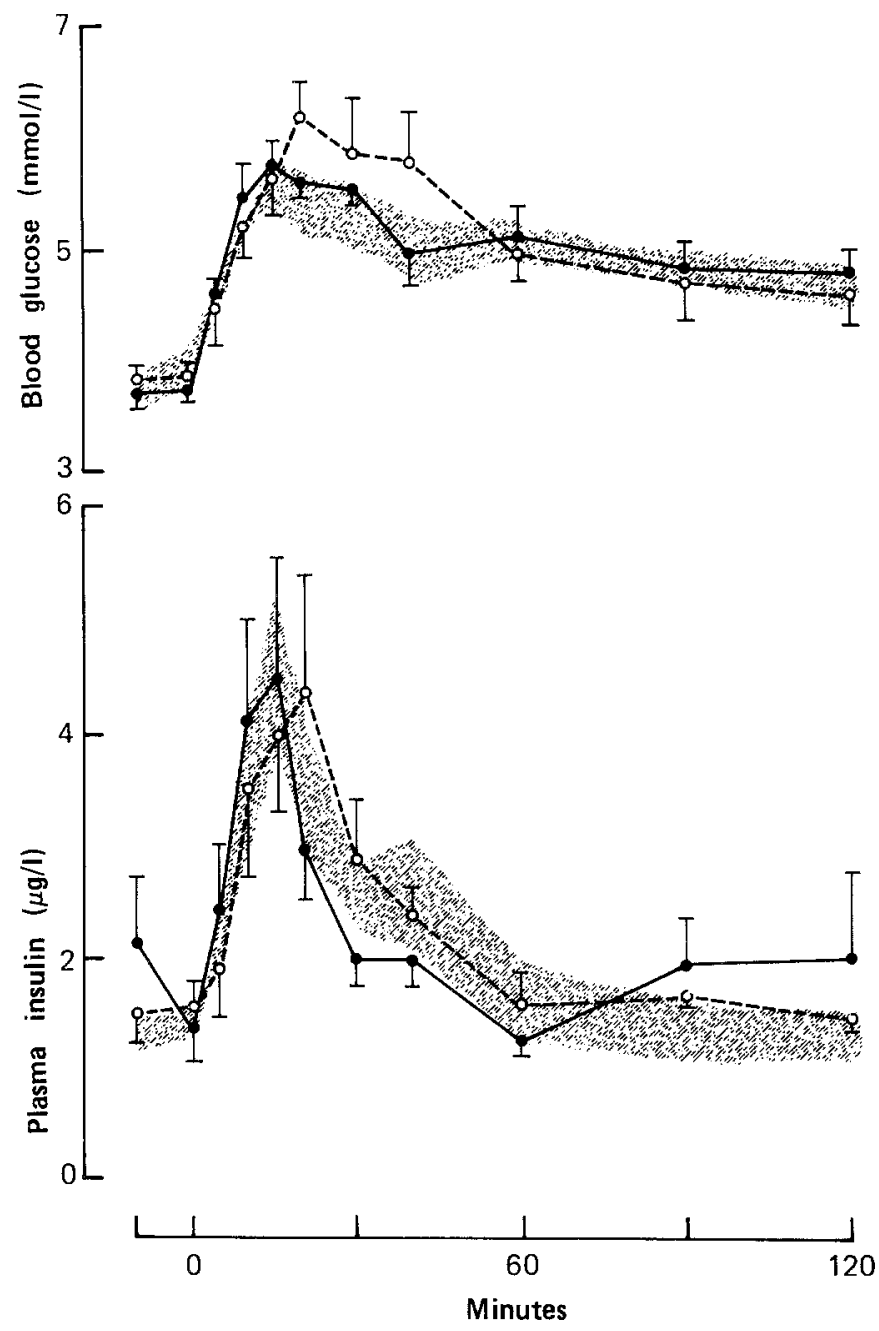

Fig. 1. Blood glucose and plasma insulin responses in rats induced to drink $300 \mathrm{mg}$ glucose. $\longrightarrow$ Splenic pulp islet-transplanted rats $(n=9), \quad 0_{--} \mathrm{O}$ renal capsule islet-transplanted rats $(n=8)$. Mean \pm SEM. The hatched area represents mean \pm SEM for the normal control rats $(n=10)$

ference in peripheral insulin levels was found throughout the test (Fig. 1). The median peak insulin response in normal and renal and splenic islet-transplanted animals occurred at $15 \mathrm{~min}$.

\section{Blood intermediary metabolite concentrations}

The 24-h fasted and fed ad libitum blood lactate, pyruvate and alanine concentrations in the experimental animals are shown in Table 1. No significant difference was found in any of the metabolites between the two groups of experimental animals and the controls.

\section{Skeletal muscle and liver glycogen}

Skeletal muscle glycogen content was the same in kidney capsule, splenic pulp islet-transplanted and normal rats, in both those fed ad libitum and those fasted for $24 \mathrm{~h}$ (Table 2). Liver glycogen in the ad libitum fed kid-
Table 1. Fasting plasma insulin concentrations, and fasting and fed blood glucose and intermediary metabolite levels in normal control rats and animals receiving islet transplants beneath the kidney capsule or into the splenic pulp

\begin{tabular}{llll}
\hline & $\begin{array}{l}\text { Normal } \\
\text { control rats }\end{array}$ & $\begin{array}{l}\text { Renal } \\
\text { islet-trans- } \\
\text { planted rats }\end{array}$ & $\begin{array}{l}\text { Splenic } \\
\text { islet-trans- } \\
\text { planted rats }\end{array}$ \\
\hline 24-h fasted rats & & & \\
Insulin $(\mu \mathrm{g} / \mathrm{l})$ & $1.45 \pm 0.14$ & $1.57 \pm 0.23$ & $1.29 \pm 0.21$ \\
Glucose $(\mathrm{mmol} / \mathrm{l})$ & $4.0 \pm 0.1$ & $3.8 \pm 0.2$ & $3.8 \pm 0.1$ \\
Lactate $(\mathrm{mmol} / \mathrm{l})$ & $1.00 \pm 0.07$ & $0.89 \pm 0.11$ & $0.90 \pm 0.09$ \\
Pyruvate $(\mathrm{mmol} / \mathrm{l})$ & $0.15 \pm 0.01$ & $0.13 \pm 0.01$ & $0.13 \pm 0.01$ \\
Alanine $(\mathrm{mmol} / \mathrm{l})$ & $0.31 \pm 0.01$ & $0.33 \pm 0.02$ & $0.36 \pm 0.03$ \\
Rats fed ad $\mathrm{libitum}$ & & & \\
Glucose $(\mathrm{mmol} / 1)$ & $5.4 \pm 0.4$ & $5.4 \pm 0.2$ & $5.6 \pm 0.4$ \\
Lactate $(\mathrm{mmol} / \mathrm{l})$ & $1.46 \pm 0.14$ & $1.36 \pm 0.14$ & $1.25 \pm 0.14$ \\
Pyruvate $(\mathrm{mmol} / \mathrm{l})$ & $0.13 \pm 0.01$ & $0.11 \pm 0.01$ & $0.09 \pm 0.01$ \\
Alanine $(\mathrm{mmol} / \mathrm{l})$ & $0.40 \pm 0.03$ & $0.43 \pm 0.03$ & $0.41 \pm 0.03$ \\
\hline
\end{tabular}

Results expressed as mean \pm SEM. $n=>8$ in each group

Table 2. Skeletal muscle and liver glycogen levels in normal control rats, and rats with islets transplanted beneath the kidney capsule or into the splenic pulp

\begin{tabular}{llll}
\hline & $\begin{array}{l}\text { Normal } \\
\text { control rats } \\
(n=9)\end{array}$ & $\begin{array}{l}\text { Renal } \\
\text { islet-trans- } \\
\text { planted rats } \\
(n=8)\end{array}$ & $\begin{array}{l}\text { Splenic } \\
\text { islet-trans- } \\
\text { planted rats } \\
(n=8)\end{array}$ \\
\hline $\begin{array}{l}\text { 24-h fasted rats } \\
\text { Liver }(\mu \mathrm{mol} / \mathrm{g} \text { wet weight })\end{array}$ & $20 \pm 3$ & $19 \pm 1$ & $19 \pm 1$ \\
$\begin{array}{l}\text { Rats fed ad libitum } \\
\text { Liver }(\mu \mathrm{mol} / \mathrm{g} \text { wet weight })\end{array}$ & $352 \pm 10$ & $297 \pm 13^{\mathrm{a}}$ & $336 \pm 11$ \\
$\begin{array}{l}\text { Skeletal muscle } \\
(\mu \mathrm{mol} / \mathrm{g} \text { wet weight })\end{array}$ & $28 \pm 1$ & $29 \pm 1$ & $25 \pm 2$ \\
\hline
\end{tabular}

Results expressed as mean \pm SEM. ${ }^{a} p<0.01$ compared with control rats, and $p<0.05$ compared with splenic pulp-transplanted animals

Table 3. Glucose turnover and glucose carbon recycling in normal control and renal capsule or splenic pulp islet-transplanted rats after a 24-h fast

\begin{tabular}{lllll}
\hline & $\begin{array}{l}\text { Plasma } \\
\text { glucose } \\
(\mathrm{mmol} / \mathrm{l})\end{array}$ & $\begin{array}{l}{ }^{3} \mathrm{H} \text {-glucose } \\
\text { turnover } \\
(\mu \mathrm{mol} \cdot \\
\left.\mathrm{min}^{-1} \cdot \mathrm{kg}^{-1}\right)\end{array}$ & $\begin{array}{l}{ }^{14} \mathrm{C} \text {-glucose } \\
\text { turnover } \\
(\mu \mathrm{mol} \cdot \\
\left.\mathrm{min}^{-1} \cdot \mathrm{kg}^{-1}\right)\end{array}$ & $\begin{array}{l}\text { Glucose } \\
\text { recycling } \\
(\%)\end{array}$ \\
\hline $\begin{array}{c}\text { Normal rats } \\
(n=15)\end{array}$ & $5.8 \pm 0.1$ & $37.0 \pm 0.9$ & $28.9 \pm 1.0$ & $22.1 \pm 1.8$ \\
$\begin{array}{c}\text { Renal trans- } \\
\text { planted rats } \\
(n=11)\end{array}$ & $5.9 \pm 0.1$ & $34.1 \pm 1.5$ & $26.8 \pm 0.8$ & $20.7 \pm 1.8$ \\
$\begin{array}{c}\text { Splenic trans- } \\
\text { planted rats } \\
(n=11)\end{array}$ & $6.1 \pm 0.1$ & $37.1 \pm 1.0$ & $28.9 \pm 0.8$ & $21.9 \pm 2.4$ \\
\hline
\end{tabular}

Results expressed as mean \pm SEM

ney capsule islet-transplanted animals was significantly less than that of the controls $(297 \pm 13$ versus $352 \pm$ $10 \mu \mathrm{mol} / \mathrm{g}$ wet weight; $p<0.01$ ) and splenic pulp islettransplanted animals $(336 \pm 11 \mu \mathrm{mol} / \mathrm{g}$ wet weight; $p<0.05$ ). After $24 \mathrm{~h}$ of fasting, similar low levels were seen in all three groups (Table 2). 


\section{Glucose turnover and recycling}

Plasma glucose concentration, turnover and recycling in animals with islets transplanted under the renal capsule (peripheral insulin delivery) were not significantly different from those of splenic pulp islet transplanted or normal control rats (Table 3 ).

\section{Discussion}

We have shown that islet transplantation under the renal capsule or into the splenic pulp can result in normal blood glucose levels in severely diabetic rats. The severity of the diabetes was confirmed by the development of fatal ketoacidosis when insulin was withdrawn from untransplanted animals, and absence of B cells on histological examination of the pancreas of transplanted animals [18].

The blood glucose response to an oral glucose load was similar between the experimental animals, and was achieved with identical peripheral insulin profiles (Fig. 1). The findings contrast with those of Brown et al. [19], who used a smaller dose of streptozotocin, found some recovery of endogenous insulin secretion, and reported elevated peripheral plasma insulin levels when fetal pancreases were transplanted under the kidney capsule. In those studies, however, the plasma glucose response was not normalised until the renal venous drainage was diverted into the portal circulation.

Also using a smaller dose of streptozotocin, other workers reported normal insulin levels with normal intravenous glucose tolerance in kidney capsule isletgrafted rats [20]. If these results are applicable in man, they suggest, together with our own observations, that factors other than the route of insulin delivery may account for the peripheral hyperinsulinaemia necessary for normoglycaemia in diabetic patients [5-7]. Such factors might include periods of hyper- and hypo-insulinization relative to blood glucose levels, and the duration of normoglycaemia or extent of the previous disturbance of control. In contrast to our own acute studies in normoglycaemic diabetic man [5] and similar studies in diabetic dogs [9], blood gluconeogenic precursor levels were normal during peripheral insulin delivery after medium-term normoglycaemia in islet-transplanted rats. In man, however, we have noted previously the positive relationship between blood lactate and plasma insulin between and within individuals $[21,22]$, and a decrease towards normal of blood lactate and pyruvate with improved metabolic control on continuous subcutaneous insulin infusion [22]. It remains unclear whether it is normoinsulinaemia or long-term normoglycaemia which is important for normalization of blood lactate levels.

Lactate turnover is unfortunately difficult to measure due to rapid equilibration with other substrates, its mainly intracellular location and a very fast turnover. Increased blood lactate concentrations in diabetic man might be the result of decreased hepatic uptake, but the latter is believed to be concentration-dependent and independent of insulin. With decreased non-esterified fatty acid supply to skeletal muscle during intensive insulin therapy [5], and as glycogen synthetase activity may be reduced as a result of previously poor diabetic control [23], more of the glucose taken up by muscle will be oxidised to lactate and pyruvate rather than incorporated into glycogen. Lactate and pyruvate release will, however, only be increased if the rate of glycolytic flux is increased relative to the metabolism of these substrates through insulin-sensitive pyruvate dehydrogenase $[24,25]$.

In the rats used in this study, the skeletal muscle glycogen levels were normal (Table 2), consistent with the plasma insulin concentrations. Decreased liver glycogen concentrations in the fed state in the kidney capsule islet-transplanted animals does, however, suggest that the liver is relatively hypoinsulinaemic, as might be expected with peripheral insulin administration.

In three studies reporting abnormal metabolite levels during acute normoglycaemia achieved with peripheral insulin infusion $[5,8,10]$, suppression of glucose carbon recycling was also noted in association with normal glucose turnover. In two of these studies [5, 8], this was accompanied by raised peripheral insulin levels and suppressed lipolysis. The reduced glucose carbon recycling is not necessarily inconsistent with the suggestion of increased lactate turnover, as decreased non-esterified fatty acid supply to the liver would be expected to divert labelled gluconeogenic precursors into the tricarboxylic acid cycle. In two of the studies [5, 10], blood glucose was restored to normal immediately prior to study with high doses of insulin. This would be expected to promote hepatic glycogen formation, and this unlabelled glycogen could make a larger contribution to overall hepatic glucose output. Further dilution of the ${ }^{14} \mathrm{C}$-label might occur through breakdown of tissue protein.

In the current study, the only report of medium-term peripheral insulin delivery with normoglycaemia, glucose turnover and glucose carbon recycling were found to be normal and similar to the values obtained by other workers in rats $[26,27]$. With normal peripheral insulin profiles and normal peripheral tissue sensitivity to insulin, a normal pattern of glucose utilisation would be expected. Normal peripheral insulin levels would, however, suggest relative hepatic hypoinsulinaemia due to abolition of the porto-peripheral gradient, and this would be expected to lead to increased hepatic glucose output. As glucose turnover is normal and as substrate supply appears normal (although gluconeogenic precursor flux was not measured), it would appear that there is increased hepatic sensitivity to insulin, unless insulin levels above those seen in the periphery are not needed for normal metabolic regulation at the liver.

An alternative explanation could lie in a disturbance of glucagon secretion. Though host pancreatic glucagon 
secretion may be preserved after $65 \mathrm{mg} / \mathrm{kg}$ of streptozotocin [28], it is possible that the $150 \mathrm{mg} / \mathrm{kg}$ we used may have impaired A cell secretion significantly and disturbed paracrine communication. If this is the case, then peripheral insulin delivery from the islet graft might be associated with peripheral glucagon delivery, and a compensatory disturbance of the latter's portoperipheral gradient [29]. Equivalent heptic glucose output might then be maintained at lower than normal insulin levels. Our finding by immunoperoxidase staining [18] of preserved glucagon-containing cells in the pancreas suggests at least the potential for continuing portal glucagon delivery.

Acknowledgements. Y.T.K. is a Medical Research Council Research Fellow. P. D. H. is a Wellcome Trust Senior Research Fellow in clinical science. The study was supported by the Newcastle Area Health Authority, the Wellcome Trust and the British Diabetic Association. Mr. D. Alderson is thanked for advice on islet transplantation techniques, and Mrs. D. Nicholson for willing technical assistance.

\section{References}

1. Blackard WG, Nelson NC (1970) Portal and peripheral vein immunoreactive insulin concentrations before and after glucose infusion. Diabetes 19: 302-306

2. Misbin RI, Merimee TJ, Lowenstein JM (1976) Insulin removal by isolated perfused rat liver. Am J Physiol 230: 171-177

3. Jaspan T, Polonsky K (1982) Glucose ingestion in dogs alters the hepatic extraction of insulin. In vivo evidence for a relationship between the biological action and extraction of insulin. J Clin Invest 69: 516-525

4. Waldhäusl WK, Gasic̀ S, Bratusch-Marrain P, Nowotny P (1983) The $75 \mathrm{~g}$ oral glucose tolerance test: effect on splanchnic metabolism of substrates and pancreatic hormone release in healthy man. Diabetologia 25: 489-495

5. Nosadini R, Noy GA, Nattrass M, Alberti KGMM, Johnston DG, Home PD, Ørskov H (1982) The metabolic and hormonal response to acute normoglycaemia in Type 1 (insulin-dependent) diabetes. Studies with a glucose controlled insulin infusion system (artificial endocrine pancreas). Diabetologia 23:220-228

6. Hanna AK, Zinman B, Nakhooda AF, Minuk HL, Stokes EF, Albisser AM, Leibel BS, Marliss EB (1980) Insulin, glucagon and amino acids during glycaemic control by the artificial pancreas in diabetic man. Metabolism 29: 321-332

7. Rizza RA, Gerich JE, Haymond MW, Westland RE, Hall LD, Clemens AH, Service FJ (1980) Control of blood sugar in insulin-dependent diabetes: comparison of an artificial pancreas, continuous subcutaneous insulin infusion and intensified conventional insulin therapy. N Engl J Med 303: 1313-1318

8. Stevenson RW, Parsons JA, Alberti KGMM (1983) Effect of intraportal and peripheral insulin on glucose turnover and recycling in diabetic dogs. Am J Physiol 244: E190-E195

9. Stevenson RW, Ørskov H, Parsons JA, Alberti KGMM (1983) Metabolic responses to intraduodenal glucose loading in insulininfused diabetic dogs. Am J Physiol 245: E200-E208

10. Freyse EJ, Fischer U, Albrecht G (1983) Glucose metabolism studied isotopically in diabetic dogs: effect of restoration of peripheral normoinsulinaemia by the artificial B cell. Diabetologia 25 : $411-417$

11. Hellerström C, Lewis N, Borg H, Johnson R, Freinkel N (1979) Method for large-scale isolation of pancreatic islets by tissue culture of fetal rat pancreas. Diabetes 28: 769-776

12. Somogyi MJ (1945) Determination of blood sugar. J Biol Chem 160: $69-73$
13. Shipley RA, Clark RE (1972) Tracer methods for in vivo kinetics. Academic Press, New York, pp 111-127

14. Streja DA, Steinger G, Marliss EB, Vranic M (1977) Turnover and recycling of glucose in man during prolonged fasting. Metabolism 26: $1089-1097$

15. Keppler D, Decker K (1974) Glycogen determination with amyloglucosidase. In Bergmeyer HU (ed) Methods of enzymatic analysis. Academic Press, New York, London, pp 1127-1131

16. Lloyd B, Burrin J, Smythe P, Alberti KGMM (1978) Enzymatic fluorimetric continuous flow assays for blood glucose, lactate, pyruvate, alanine, glycerol and 3-hydroxybutyrate. Clin Chem 24: $1724-1729$

17. Heding LG (1972) Determination of total serum insulin (IRI) in insulin treated diabetic patients. Diabetologia 8: 260-266

18. Kruszynska YT, Home PD, Alberti KGMM (1984) An animal model of peripheral and portal insulin delivery from transplanted islets. Diabetologia 27:300A

19. Brown T, Mullen Y, Clark WR, Molnar JG, Heininger D (1979) Importance of hepatic portal circulation for insulin action in streptozotocin diabetic rats transplanted with fetal pancreases. $J$ Clin Invest 64: 1688-1694

20. Reece-Smith H, McShane P, Morris PT (1982) Glucose and insulin changes following a renoportal shunt in streptozotocin diabetic rats with pancreatic islet isografts under the kidney capsule. Diabetologia 23: 343-346

21. Home PD, Capaldo B, Nosadini R, Massi-Benedetti M, Burrin JM, Noy GA, Nattrass M, Johnston DG, Alberti KGMM (1982) Studies on intermediary metabolism using closed-loop control of blood glucose concentration. In: Brunetti P, Alberti KGMM, Albisser AM, Hepp KD, Massi-Benedetti M (eds) Artificial systems for insulin delivery. Raven Press, New York, pp 505-512

22. Home PD, Capaldo B, Alberti KGMM (1983) The quality of metabolic control during open-loop insulin infusion in Type 1 diabetes. In: Mngola E (ed) Diabetes 1982. International Congress Series 600. Excerpta Medica, Amsterdam, pp 295-301

23. Roche Norlund AE, Bergstrom J, Hultman E (1972) Muscle glycogen and glycogen synthetase in normal subjects and in patients with diabetes mellitus. Scand J Clin Lab Invest 30: 77-84

24. Fuller SJ, Randle PJ (1984) Reversible phosphorylation of pyruvate dehydrogenase in rat skeletal-muscle mitochondria. Effects of starvation and diabetes. Biochem J 219: 635-646

25. Denton RM, Halestrap AP (1979) Regulation of pyruvate metabolism in mammalian tissues. Essays Biochem 15: 37-74

26. Katz J, Dunn A, Chenoweth M, Golden S (1974) Determination of synthesis, recycling and body mass of glucose in rats and rabbits in vivo with ${ }^{3} \mathrm{H}$ - and ${ }^{14} \mathrm{C}$-labelled glucose. Biochem $\mathrm{J}$ 142: 171-183

27. Okajima F, Ui M (1979) Metabolism of glucose in hyper- and hypo-thyroid rats in vivo. Glucose turnover values and futile cycle activities obtained with ${ }^{14} \mathrm{C}$ - and ${ }^{3} \mathrm{H}$-labelled glucose. Biochem $\mathrm{J}$ 182: $565-575$

28. Inoue S, Kajinuma H, Morita T, Mullen YS (1983) Restoration of insulin and glucagon release by fetal pancreatic transplantation in diabetic rats. In: Sakamoto N, Alberti KGMM (eds) Current and future therapies with insulin. International Congress Series 607. Excerpta Medica, Amsterdam, pp 384-389

29. Jaspan JB, Huen AHJ, Morley CG, Moossa AR, Rubenstein A (1977) The role of the liver in glucagon metabolism. J Clin Invest 60: $421-428$

Received: 24 August 1984

and in revised form: 8 February 1985

Dr. Y.T. Kruszynska

Department of Medicine

Royal Victoria Infirmary,

Newcastle upon Tyne NE1 4LP, UK 